\title{
PROPOSAL FOR THE IMPLEMENTATION OF THE EUROPEAN RAIL TRAFFIC MANAGEMENT SYSTEM (ERTMS) TO THE RAILWAY NETWORK IN THE REPUBLIC OF CROATIA
}

\author{
Tomislav Josip Mlinaric, Bozica Rados \& Marko Vajdic
}
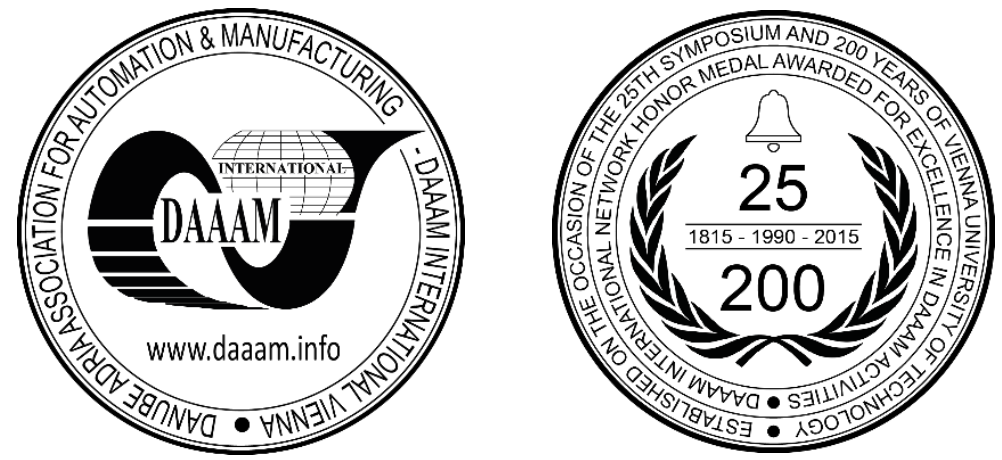

This Publication has to be referred as: Mlinaric, T[omislav] J[osip]; Rados, B[ozica] \& Vajdic, M[arko] (2017). Proposal for the Implementation of the European Rail Traffic Management System (ERTMS) to the Railway Network in the Republic of Croatia, Proceedings of the 28th DAAAM International Symposium, pp.0109-0117, B. Katalinic (Ed.), Published by DAAAM International, ISBN 978-3-902734-11-2, ISSN 1726-9679, Vienna, Austria DOI: $10.2507 / 28$ th.daaam.proceedings.014

\begin{abstract}
The European Rail Traffic Management System (ERTMS) is a project promoted by the European Union (EU) with aim to increase security and interoperability and reduce the cost of maintaining railway systems in Europe. The aim of ERTMS is to replace the traditional signal-security systems of individual countries and to enable the creation of a single integrated European rail system which would result in increased competitiveness of European railways at the interstate level. For Croatia as an EU member through the European Corridors TEN-T, implementation of ERTMS is necessary in order to better integrate the Croatian railway network into a single European network. This work will present a deep analysis of the current status of the railway network as well as strategies for further implementation and integration of the ERTMS system into the railway network in Croatia.
\end{abstract}

Keywords: ERTMS; GSM-R; ETSC; interoperability; safety

\section{Introduction}

European Rail Traffic Management System (ERTMS) is a project induced by the EU with an objective to increase security and interoperability, and to reduce maintenance costs of railway systems in Europe, thus harmonizing the technical railway standards between the Member States. The reduction of railway traffic in international traffic is caused by the popularity increase of road and air traffic, whose advantages with border crossings have made the railways uncompetitive. This policy's objective is to bridge the gaps between traffic networks of Member States, to remove the bottlenecks that still hamper the smooth functioning of the internal market and to overcome technical obstacles.

The main goal of ERTMS is to replace the traditional signal-security systems of individual states and to enable the creation of a unified integrated European railway system that would result in the increase of European railway competitiveness on international level. [1]

After analysing of the current situation and future capacity needs and demands expected from the railway in Croatia, it can be concluded that the implementation of the ERTMS is one of the necessary measures with the aim to eliminate potential bottlenecks on the network, increases current capacity of the railway network in whole, improve the 
interoperability of railway transport, increase of competitiveness of the railway network and significantly raise the level of quality and safety. Moreover, in order to integrate the national railway network into unified European network and satisfy the defined technical conditions for the base and overall TEN-T corridors (the Mediterranean Corridor and the Rhine-Danube Corridor), the authors of this article proposed the phasing (working steps) and optimal time schedule for the implementation of the ERTMS system on the Croatian railway network.

\section{ERTMS-European Rail Traffic Management System}

European Rail Traffic Management System (ERTMS) is composed out of two systems: European Train Control System (ETCS) and Global System for Mobile Communications - Railways (GSM-R).

European Union has launched, with Directive 96/48/EZ from 23 July 1996 about the interoperability of TransEuropean railway system of fast trains and Directive 2001/16/EZ from 19. March 2001 about the interoperability of Trans - European conventional railway system, a procedure that would enable daily use of different railway systems of Member States, thus enabling safer and undisturbed passage from one national railway network to another. Within the scope of these Directives, several technical solutions were devised (TSIa). Those solutions primarily refer to basic elements, such as train operation and their safety, telematics applications in freight transport, professional qualifications of employees in international traffic, freight wagons and sound emissions.

In order to reduce technical obstacles of train interoperability the representatives of the railway sector and the Commission have signed, in 2005, 2008 and 2012, Memorandums about introduction and development of the European system of railway signalization ERTMS/ETCS. They were aiming to harmonize twenty different systems of signalization, which currently exist in Europe, and to implement an automatic and uniform speed check, which is based on technological achievements in the field of telecommunications. In 2009, the European Commission adopted a European plan for the gradual introduction of the ERTMS system into the major European corridors within a decade.

During 2013 the European Commission and the ministers of traffic of Member States of the EU have made a final decision about the guidelines of EU's new traffic policy. The Regulation was adopted, (EU) No. 1316/2013 of the European parliament and the Council from 11th December 2013, about the establishment of an Instrument for Connecting Europe, the amendment of the Regulation(EU) No. 913/2010 and the repeal of the Regulations (EC) No. 680/2007 and (EC) No. 67/2010. This Regulation has connected the existing traffic network of European roads into a Trans-European traffic network [2], [3].

The aim of creating a unified traffic network is to remove bottlenecks on European traffic routes, improve the infrastructure and connect different types of transport into a multimodal traffic across the EU.

Considering that the Directive 2008/57/EZ has been significantly changed several times, due to clarity and understanding of further changes, the Directive on $11^{\text {th }}$ May 2016 has been modified into Directive (EU) 2016/797. This Directive determines the conditions that must be fulfilled in order to achieve interoperability in the EU's railway system in accordance with the Directive (EU) 2016/798 in order to define the optimal level of technical harmonization, enable facilitation, improvement and development of railway transport in the EU and with other non-Member States, thus contributing to the completion of a unified European railway space and a gradual creation of internal market. These conditions are referring to planning, construction, putting in use, modernization, renewal, work and maintenance of parts of that system, professional qualifications, health and safety conditions which are applied to employees and benefit their work and maintenance. This Directive for each subsystem sets out the provisions on the interoperability constituents, interfaces and procedures and the conditions for the overall compatibility of the railway system of the Union which are necessary to achieve interoperability.

ERTMS is the European standard for ATP that enables the interoperable system of railways in Europe.

ERTMS and ATP are security systems that enable the conformity of trains with speed limitations and signalization.

The purpose of the system is to help in the area of signalization and in the system of train management, which represents one of the biggest obstacles in development of railway traffic. Unification of multiple signalization systems will improve competitiveness and enable better interoperability of freight and passenger traffic. Furthermore, it will also encourage European market of railway equipment, reduce costs and improve overall quality and security of railway traffic.

ETCS is an automated system of train protection that is based on the signalization in driver's cabin and constant data transmission between the tracks and the train. [4].

It secures safe train traffic in all conditions by supplying the driver directly with data on the screen in driver's cabin and by constantly monitoring driver's actions.

The result of work by the European Commission and other telecommunications entities involved was the definition of GSM for railway (GSM-R) as digital radio platforms for railway's internal voice and data transmission, and enabling the function of provider for ETCS as a common CCS.

GSM-R and ETCS are integrated in a system of communication and signalization ERTMS.

Current mobile network GSM-R is a result of years of collaboration between several Europe's railway operators, railway industry and standardization bodies. Common goal is to achieve interoperability throughout Europe via one communication platform. 


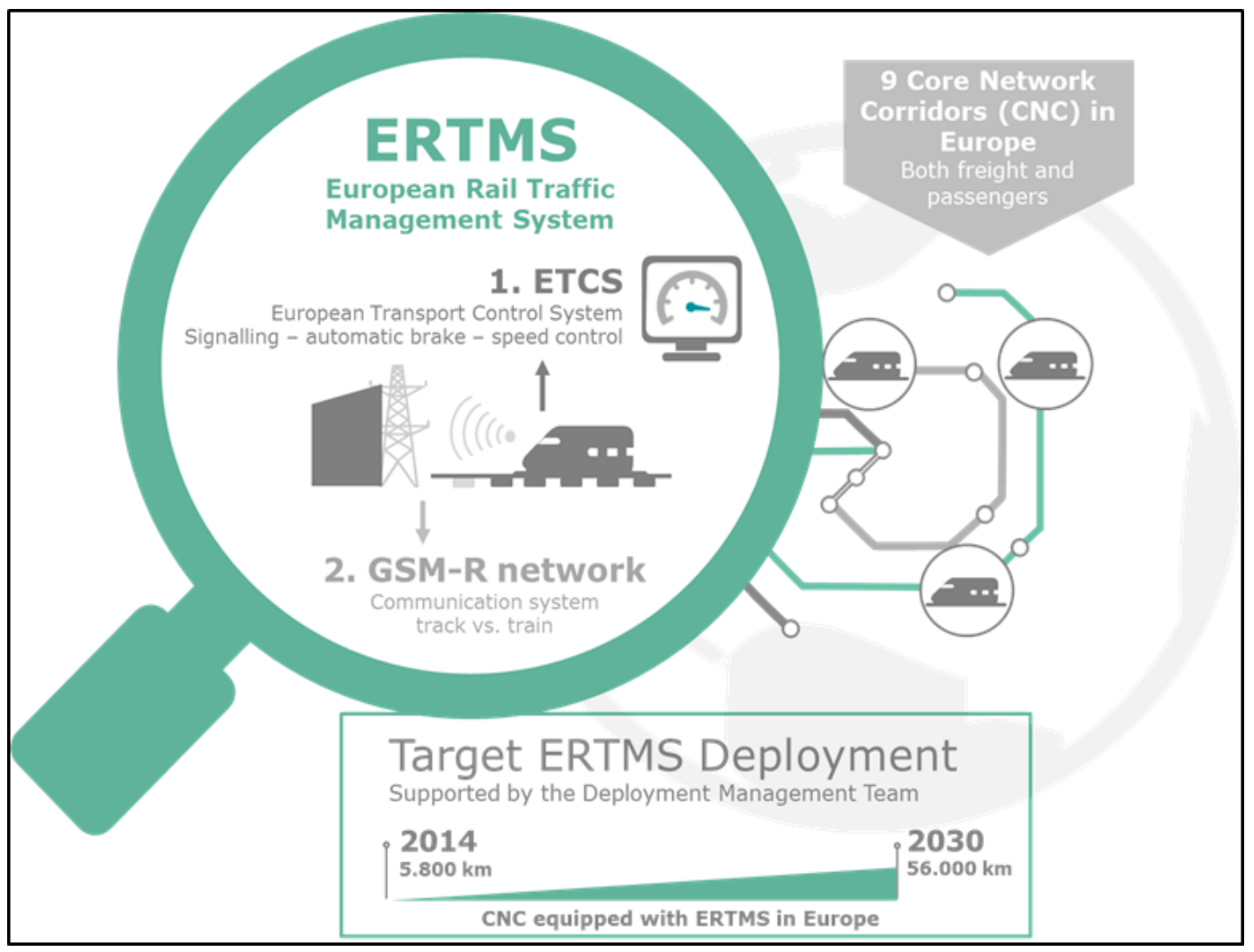

Fig. 1. ERTMS - European Rail Traffic Management System

Source: European Commission - Mobility and Transport -2016

The current GSM-R standard encompasses the key functionalities and experiences of analogue radio systems that were used throughout Europe.

GSM-R platform enables a safe platform for voice and data transmission between the staff and the railway operator. The network supports advanced features such as dual voice calls, conference calls, location-based connections, priority calls, and emergency call retrieval. These functions significantly improve communication, collaboration and security aspects for railway operative staff.

As a part of ERTMS standard, GSM-R signal transmits information directly to the unit in the train, enabling higher train speeds and traffic density with high level of security.

The communication's platform for railway networks uses GSM technologies and specific applications for railway traffic management. GSM-R is developed under the sponsorship of the EU in order to successfully resolve the challenges of railway development, such as:

- interoperability with national and international communication systems of railway networks

- improved efficiency, security and reliability, with it passenger satisfaction

- differentiation of value added services in order to increase customer loyalty and research of other sources of revenue

GSM-R has already fulfilled the expectations in the first and second phase of implementation in Europe, and now operators in numerous countries around the world are implementing it.

GSM-railway is an international standard for wireless railway communication and applications. System ERTMS is used for the communication between the train and railway's control centres. It is based, inter alia, on the GSM technology and specifications of EIRENE and MORANE, which ensure accessibility even when the vehicle is moving up to 500 $\mathrm{km} / \mathrm{h}$ without loss of communication.

\section{ERTMS-corridors}

"Corridors of base network" are introduced as a platform for a unified basic network[5]. They encompass public and private funds concentrating the support of the EU from CEF (Connecting Europe Facility), especially regarding the following:

- removal of bottlenecks

- construction of missing cross-border connection

- promotion of modal integration and interoperability 
Their goals also include:

- integration of railway corridors for freight traffic (as a permanent modal measure, these corridors will be integrated into the multimodal TEN-T network)

- $\quad$ promotion of clean fuels

- $\quad$ other innovative traffic solutions

- improvement of telematic applications for efficient use of infrastructure

- integration of urban areas into a TEN-T network

- $\quad$ improvement of security

Nine corridors of the core network, which are set out in the Amendment of the Regulation about the establishment of the Instrument for Connecting Europe that includes the list of projects predetermined for potential financing from the EU during a period from 2104 to 2020, are determined based on their additional value for the development of TEN-T and on their maturity status.

\section{TEN-T program:}

The European Commission has created the TEN-T program in order to support the construction and the renewal of traffic infrastructure throughout the European Union.

TEN-T program is dedicating financial support in the realisation of important projects of traffic infrastructure - in accordance with the general scope of European competitiveness, job creation and cohesion.

\section{Advantages of railway line equipped with ERTMS:}

- The advantages that are expected from ERTMS can be summarized as follows: [6]

- Cross-border interoperability;

- Improving security in national and international railway traffic;

- Improvement of the management of international passenger and freight railway traffic;

- A shorter time interval of trains on railway lines with dense traffic, driving in APB mode, enabling the usage of maximum railway line capacity;

- The possibility of gradual implementation of a new technology;

- Enabling a Pan-European market competition among ERTMS/ETCS component manufacturers. Strengthening the position of the European railway industry in the world market;

- Enabling the preconditions for future harmonization in other areas of rail traffic management;

- The possibility to optimize traffic capacity.

\section{The position of the Republic of Croatia in trans-European traffic network of Europe (TEN-T)}

Connecting the core network of traffic infrastructure with trans-European networks and corridors is one of the main goals and an important prerequisite for an even development of all EU Member States. Thus, the EU continually invests efforts, in sync with the increasing number of Member States, in enablement of the construction of necessary roads and in integration of national road networks into a Trans-European road network TEN-T. Formation of this European road network will remove bottlenecks and connect distant regions into a common system of roads. TEN-T, in accordance with the proposition of Regulation about EU guidelines for the development of Trans-European road network from 19 October 2011 and with CEF, should be developed based on dual-layer approach, consisting from overall and base network.

The overall network represents the general layer of TEN-T and includes all the existing and planned infrastructure that complies with the prerequisites of the Guidelines, and needs to be finished as late as 31 December 2050. According to earlier interpretations of the European Commission, for Croatia it should be the network agreed in the frame P21 of the Trans-European network.

The basic network includes only the parts of the overall network that are strategically most important ones, and should be finished as late as 31 December 2030. The Decision of the European Commission from 18 October 2013 defines nine corridors of the Basic EU road network. They act as a basis for the connection of 94 main European ports and 38 key airports with railway and road in the capitals of European countries (Port of Rijeka and Zagreb's airport are among them), for the development of 15 thousand kilometres of railway infrastructure capacitated for achieving satisfactory speeds for freight and passenger trains and for 35 thousand border crossings [7], [8].

The Mediterranean corridor connects the ports of the Iberian Peninsula that are Algeciras, Cartagena, Valencia, Tarragona and Barcelona via southern France, with the connection to Marseille and Lyon towards northern Italy and Slovenia, and via a branch through Croatia and Hungary to the Ukrainian border. It covers railways, roads, airports, ports and internal waterways of the river Po. Key projects are the railway in Spain according to UIC norm, the railway tunnel Lyon-Torino and the railway across the karst area of Trieste/Kopar - Ljubljana. 
The Rhine-Danube corridor connects Strasbourg and Mannheim via two parallel axes in southern Germany, one alongside the Main river and Danube river and other via Stuttgart and München, with a branch towards Prague and Žilina towards the border between Slovakia and Ukraine, through Austria, Slovakia and Hungary to Romanian ports of Constanta and Galati. It covers railways, roads, airports, ports, railway-road terminals and systems of internal waterways of river Main, channel Main-Danube, the entire stream of Danube downstream of Kelheim and of river Sava. With key projects the bottlenecks alongside the internal waterways and sections of railway lines Stuttgart-Ulm and München Freilassing are removed. [5].

\section{ERTMS implementation objectives in the Republic of Croatia}

Objectives of implementing ERTMS:

It is very important that the objectives by the implementation of the ERTMS in every country of the European Union are the same.

Croatia is an official member of the European Union since the 1st. of July 2013. Because of this is important that the objectives will be implemented.

Through the abolition of national Systems (i. e. signaling, train control and other properties) will be guaranteed the continuous train traffic in Europe and Croatia.

The following table is an investment plan by the European Union. This includes measure for the implementation:

- The enhancement in signalling (especially ERTMS)

- Renewal of tracks

- The renewal of signallong system

- The renewal of tunnel, bridge etc.

- The electrification

- The creation of siding, passing tracks, extra tracks

- The creation of a new structure (line, bridge, tunnel,)

- Adjustment of gauge

- The track enhancement

- The level crossings

- The noise reduction

- And other projects

The objectives of implementing the ERTMS in Croatia were viewed through three key goals [3]:

- Establishment of interoperability

- Safety of railway system

- Capacity increase

ERTMS implementation in Croatia will result in numerous benefits: it will contribute to the harmonization of security systems of railway lines in Europe (LEU, signalling marks, balise, RBC and Euroloop) and of trains (EVC, interface driver-machine, balise, odometer).

The national APB system will no longer be needed. The trains that are coming from Croatia will be able to cross the border faster since it will no longer be required to change the system of APB whilst crossing the border. Furthermore, drivers will no longer have to be changed at the border crossing. ETCS enables higher density of trains and increased competitiveness of the railway system. Interoperability in our case means that trains have the possibility of driving on every section of the railway line within the EU and that they can use railway systems in the EU.

The benefits for the railway sector in the Republic of Croatia will be demonstrated through the following parameters:

- greater competitiveness for the rail sector

- unified signalization standard

- facilitation of cross-border traffic

Benefits for HŽI, the infrastructure manager in the Republic of Croatia, will be manifested through the following parameters:

- $\quad$ increased security

- limitation removal

- $\quad$ higher traffic speeds

- increased capacity on the lines

- high reliability 
The benefit for railway operators in Republic of Croatia will be demonstrated by the fact that trains will be able to move across the European network equipped with ERTMS with only one signalling system, unlike the existing state in which several ATP systems have to be installed. This will reduce the costs of training and the training of train drivers and a waste of time at the borders because of the formalities and technical limitations.

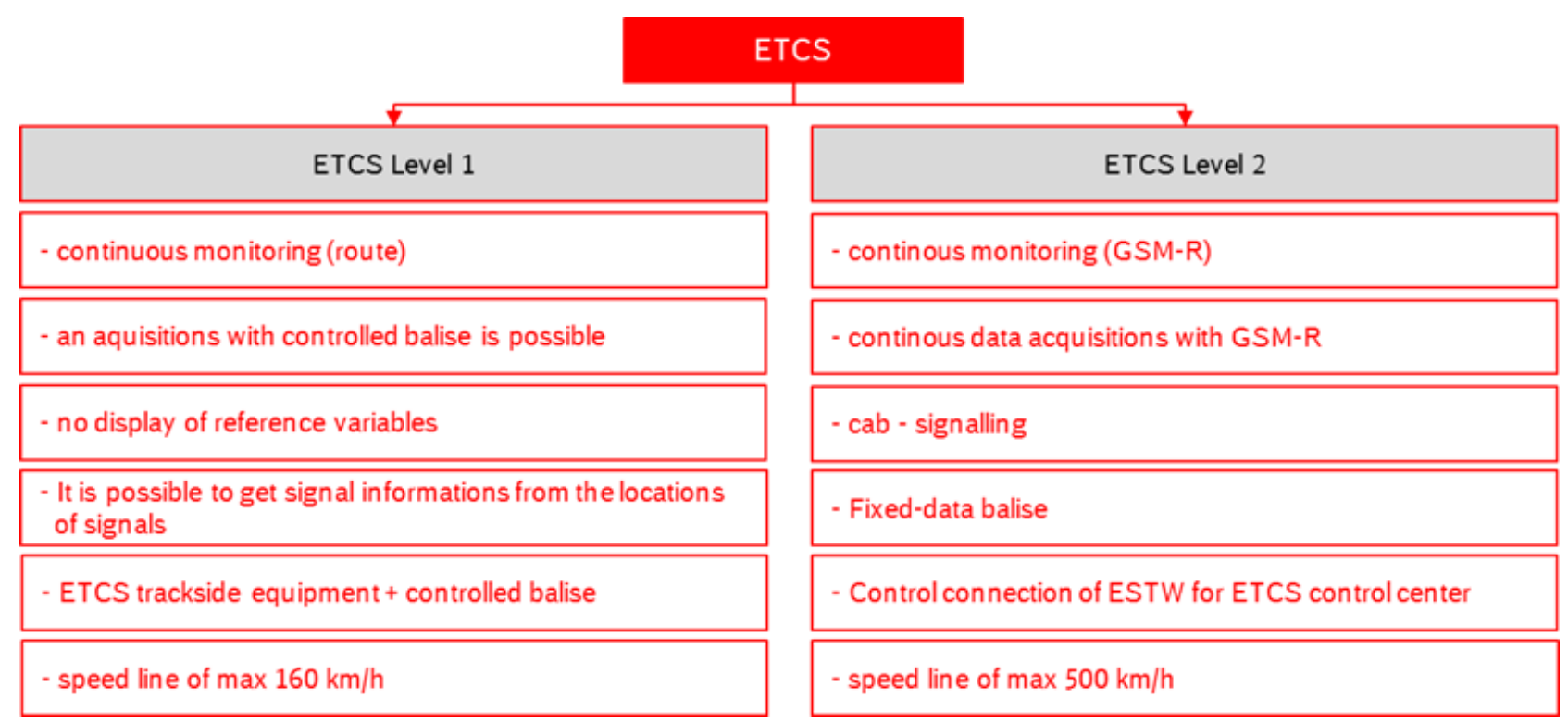

Fig. 2. Compare ETCS Level 1 and ETCS Level 2

Source: Study of implementing ERTMS in Croatia, 2016

\subsection{Gradualness (phase) of ERTMS introduction in the network of the Republic of Croatia}

Due to the aforementioned, [9], [10] in order to implement ERTMS in the Republic of Croatia the following items have to be considered:

1. Given the state of the signal-safety and traffic-control systems, as well as the currently open projects that are in the development stage of project documentation, it is possible to immediately access the implementation of ERTMS / ETCS level 1 on railway lines of the corridor. However, this solution does not allow, due to deterioration of SSD, a further upgrade to ERTMS / ETCS level 2.

2. The inexistence of the GSM-R network is complicating any further development or upgrade. Thus, it is recommended that the prerequisites be achieved before anything else, which are provided below in text for PHASE 1 and PHASE 2, after which it would be possible to attempt the completion of ERTMS network in Croatia. Relating to the GSM-R network, it is recommended to immediately approach the preparation / design of the network for voice and data system. Below is a description of the ERTMS implementation - choosing the right option of the proposed level, which is, as a solution, ready for only voice and/or voice + data upgrade as a solution.

\section{ERTMS implementation in phase 1}

\section{ETCS Level 1}

- Goal is to provide main international corridors RH 1 and RH 2 with continuous ETCS L1

- Design, procurement and construction of ETCS L1 in network gaps

- GSM-R (voice only)

- Parallel roll-out of GSM-R for main international corridors RH 1 and RH 2

- Setup of GSM-R core system with scalable upgrade option for nationwide roll-out

- Start and progress of roll-out depending on available funding 


\begin{tabular}{|c|c|c|c|}
\hline & $\begin{array}{c}\text { Option 1: } \\
\text { No ERTMS } \\
\text { implementation }\end{array}$ & $\begin{array}{c}\text { Option 2: } \\
\text { ETCS L1 \& } \\
\text { GSM-R (voice) }\end{array}$ & $\begin{array}{c}\text { Option 3: } \\
\text { ETCS L2 incl. } \\
\text { GSM-R (voice \& } \\
\text { data) } \\
\end{array}$ \\
\hline $\begin{array}{l}\text { RH } 1 \text { \& RH2, } \\
\text { knot ZG \& R }\end{array}$ & $\begin{array}{l}\text { - No international traffic } \\
\text { - Further reduction of traffic } \\
\text { likely } \\
\text { - Not recommended }\end{array}$ & $\begin{array}{l}\text { - Most economic option to } \\
\text { ensure international traffic } \\
\text { - Closing gaps in network } \\
\text { - Quick implementation }\end{array}$ & $\begin{array}{l}\text { - After full ETCS L1 \& GSM- } \\
\text { R voice implementation, } \\
\text { future upgrade } \\
\text { recommended }\end{array}$ \\
\hline $\begin{array}{l}\text { Lines for } \\
\text { phase } 2\end{array}$ & $\begin{array}{l}\text { Next } 10 \text { years: } \\
\text { - Further infrastructure } \\
\text { upgrading needed } \\
\text { - Electrification and } \\
\text { modernisation first }\end{array}$ & $\begin{array}{l}\text { justified } \\
\text { - Not backed up by traffic } \\
\text { forecast } \\
\text { - No financing by EU }\end{array}$ & $\begin{array}{l}\text { - After full ETCS L1 \& GSM- } \\
\text { R voice implementation, } \\
\text { future upgrade } \\
\text { recommended }\end{array}$ \\
\hline $\begin{array}{l}\text { All other } \\
\text { national } \\
\text { lines }\end{array}$ & $\begin{array}{l}\text { Further infrastructure } \\
\text { improvement recommended } \\
\text { (not part of this study) }\end{array}$ & $\begin{array}{l}\text { - Upgrading depending of } \\
\text { available national funds } \\
\text { - Non-TEN network not part of } \\
\text { this study }\end{array}$ & $\begin{array}{l}\text { - Upgrading depending of } \\
\text { available national funds } \\
\text { - Non-TEN network not part of } \\
\text { this study }\end{array}$ \\
\hline
\end{tabular}

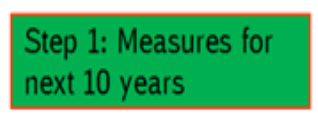

Step 2: Measures for years after first ERTMS implement
ERTMS Level 2 provides the same interoperability and safety benefits of Level 1.

Fig. 3. ERTMS implementation objectives in the Republic of Croatia Source: Study of implementing ERTMS in Croatia, 2016

5.2. ERTMS in Croatia-implementation plan for first 10 years until 2025: closing gaps in network to ensure international traffic

\section{GSM-R (voice only)}

- Parallel roll-out of GSM-R for main international corridors RH 1 and RH 2

- Setup of GSM-R core system with scalable upgrade option for nationwide roll-out

- Start and progress of roll-out depending on available funding

\section{ERTMS implementation in phase 2}

\section{Establishing interoperability}

- Enable cross-border traffic without need to install many national ATP systems

- Save time when cargo or passenger trains cross border

- Increase competitiveness for railway operators and infrastructure managers

- reduce development time and investment costs for cross-border transport vehicles

- $\quad$ simplify vehicle registration, reducing of vehicles for international traffic

\section{Increasing capacity}

- Increasing line capacity with ERTMS Level 2:

- $\quad$ higher operational speeds

- $\quad$ reduced headways

- $\quad$ increase the line speed

- - Using “moving block” technology

- $\quad$ Still in conceptual phase

- $\quad$ - No capacity increase with ERTMS Level 1, but same safety and interoperability benefits 


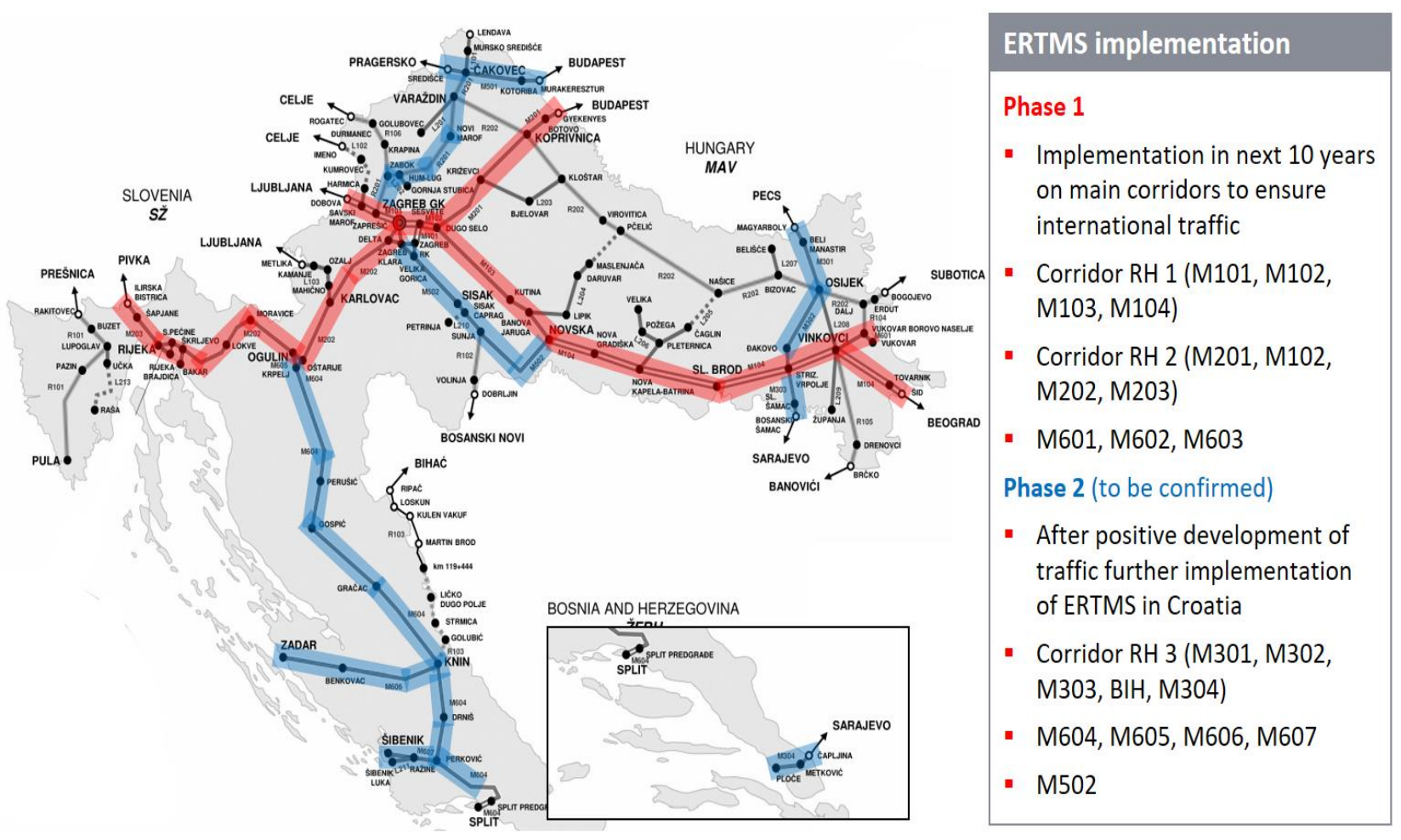

Fig. 4. ERTMS in Croatia - proposal on final implementation after 30 years Source: Study of implementing ERTMS in Croatia, 2016

\section{Enhancing safety and quality}

- One signalling and safety standard in the European Union

- replace older ATP systems with a more secure option

- One radio communication platform for all railway functions, applications and services

- Decrease risk of railway traffic accidents through continuous communication

- High security in operational communication

\subsection{Benefits for the railway sector: ERTMS introduction in the network of the Republic of Croatia}

ERTMS can make the railway sector more competitive. One of the aims of ERTMS is to facilitate cross-border traffic by standardizing the signalling systems under just one standard, and to also reduce the technical and operational complexity of trains and wagons/carriages. The traditional drawbacks of international rail traffic 1 (e.g.: different gauge, different voltage, different signalling systems at each country...) makes traffic between European states more difficult.

ERTMS is intended to facilitate cross-border traffic and interoperability, at least in signalling. Regarding the European supplier industry, ERTMS is a European open standard that has promoted the European industry worldwide due to the existence of ERTMS deployment both in Europe and on other continents.

Safety Increase: ERTMS has a higher safety level compared with most of the existing national ATP systems. This is mainly achieved through the continuous supervision of the speed of trains Higher speeds: ERTMS allows operation speeds of up to $500 \mathrm{~km} / \mathrm{h}$. This means that the signaling system installed along the side of the rail track will not hinder the maximum operation speed for ERTMS equipped vehicles. The first benefit is for the Infrastructure Manager given the elimination of this restriction. Higher capacity on lines: Depending on the previously installed system, ERTMS can reduce the minimum headway between trains (i.e.: the minimum distance or time between commercial service vehicles). This allows the Infrastructure Managers to manage a greater number of trains at the same time, and thus the railway system is able to transport of passengers or goods. Potential maintenance cost reduction: Since ERTMS (especially pure Level 2 installation) requires fewer signals at the side of the track, there is a possibility of reducing maintenance costs.

High reliability rates: this will involve achieving better punctuality for both freight and passenger services, since failures (and consequent delays) due to the signalling system can be even less likely thanks to the high safety standards of ERTMS components. 


\section{Conclusion}

ERTMS implementation in Croatia will result in numerous advantages: it will contribute to the harmonization of safety systems of railway lines in Europe (LEU, signalling marks, balise, RBC and Euroloop) and of trains (EVC, interface driver-machine, balise, odometer) and it will increase the overall availability of the railway traffic infrastructure.

After the analysis of status of HŽI network and after the processing of collected data the conclusions, upon which the following recommendations were made, are the following:

Network analysis shows that currently there is sufficient capacity for planned traffic load, but it also shows that the status of railway line's infrastructure is, on individual sections, insufficient. This significantly influences the capacity itself (reducing speed of traffic and creating bottlenecks on corridor railway lines).

Given the current state of the SS device, and the inability to repair it, the guidelines and suggestions of the author to implement the ERTMS imply the development in two phases, and according to the previously described dynamics. Concerning ETCS level 2, it is recommended for both development phases, with the note that in phase 1, where the basic corridor network is closed, it is necessary to prepare i.e. to integrate already existing installed ETCS level 1 systems in order to pass onto ETCS levels 2.

The problem of integration and transfer to interoperability are inadequate platforms, landscaped grounds and unsatisfactory access for passengers, which are a potential threat in case of unoccupied facilities. An insight into the existing state of the building and the surface for receiving and shipping passengers on railway lines reveals the diversity in the level of equipment and arrangement of these elements. Work on existing platforms and landscaped areas that are reconstructed and/or upgraded, wherever possible, is being pursued to meet the requirements, to the fullest possible extent, of the special regulations regulating railway infrastructure subsystems as well as the relevant provisions of regulations which regulate spatial planning and construction. The investment plans provide for a solution to these problems. It is therefore recommended that the prerequisites for ETSC Level 2 and GSM-R be fulfilled: construction work to be done in terms of achieving interoperability requirements (reconstruction of the railway station, etc.), in order to install electronic devices.

Finally, the authors give their recommendation, while the final decision on the development strategy will be on the side of the Investor and the relevant Ministry, as well as decision on funding sources.

\section{References}

[1] Smith, P., Majumdar, A., Ochieng, W. Y. (2012). An overview of lessons learnt from ERTMS implementation in European railways. Journal of Rail Transport Planning \& Management, Vol. 2, Issue 4, (December 2012) pp. 7987, ISSN: 2210-9706

[2] Haramina, H., Brabec, D, Grgic, D. (2012). Influence of train control system on railway track capacity, In: DAAAM international scientific book 2012, Katalinić, B. (Ed.), pp. 419-426, DAAAM International Publishing, DAAAM International Vienna, ISBN 978-3-901509-86-5, Vienna

[3] Study of implementing ERTMS in Croatia, 2016, DB E\&C, HZ Infrastructura

[4] https://ec.europa.eu/transport/modes/rail/ertms_enht, 2016, Mobility and transport, European Commission, Accessed on: 01-10-17

[5] https://ec.europa.eu/transport/themes/infrastructure/mediterranean_en , 2016, Mobility and transport, European Commission, Accessed on: 01-10-17

[6] https://ec.europa.eu/transport/themes/infrastructure/rhine-danube_en , 2016, Mobility and transport, European Commission, Accessed on: 01-10-17

[7] Haramina. H.; Brabec, D.; Štefančić, I. (2011). Influence of Train Control System Characteristic on Railway Infrastructure Capacity, Proceedings of 22nd DAAAM World Symposium "Intelligent Manufacturing \& Automation: Power of Knowledge and Creativity"Katalinic, B.(Ed)., pp. 0357-0358, ISBN 978-3901509-83-4,2326th November 2011, Vienna, Austria

[8] Zahar, N. A., Khan, S. A., Araki, K. (2012). Towards the Safety Properties of Moving Block Railway Interlocking System. International journal of innovative computing, Information and Control, Vol. 8, No. 8, (August 2012) pp. 5703-5713, ISSN 13494198

[9] UIC (2008). ETCS Implementation Handbook, ERTMS Platform, Infrastructure Department, ISBN 2-7461-14992, Paris UIC, International railways statistics, 2012

[10] Dincel, E., Kurtulan, S. (2012). Interlocking and Automatic Operating System Design with Automaton Method, Proceedings of the 13th IFSC Symposium on Control in Transportation Systems, The International Federation of Automatic Control, Stoilov, T. (Ed.), pp.191-196, ISBN 978-392823-13-7, Sofia, Bulgaria, September 2012 